\title{
Hasil Penelitian
}

\section{PERBANDINGAN KESTABILAN HEMODINAMIKA ANTARA POSISI LEFT LATERAL $15^{\circ}$ DENGAN BERBARING TERLENTANG PADA PASIEN SECTIO CAESAREA POST ANESTESI SPINAL}

\author{
Kezia Engely Natasha Latupeirissa ${ }^{1}$, Ony W. Angkejaya ${ }^{2}$ \\ ${ }^{1}$ Mahasiswa Fakultas Kedokteran Universitas Pattimura \\ ${ }^{2}$ Dosen Fakultas Kedokteran Universitas Pattimura \\ Coresponding author email: kezialatupeirissa9@gmail.com
}

\begin{abstract}
Abstrak
Skripsi ini berjudul "Perbandingan Kestabilan Hemodinamika Antara Posisi Left Lateral $15^{\circ}$ dengan Berbaring Terlentang Pada Pasien Sectio Caesarea Post Anestesi Spinal”. Skripsi ini merupakan suatu penelitian yang meneliti tentang efektivitas jumlah dosis obat efedrin yang digunakan dalam menjaga kestabilan hemodinamika yang diberikan pada pasien sectio caesarea post anestesi spinal antara posisi left lateral $15^{\circ}$ dengan berbaring terlentang di RSUD Dr. M. Haulussy Ambon. Indikator penilaian pada skripsi ini meliputi perbandingan posisi, tekanan darah, denyut nadi, dan dosis efedrin yang digunakan pada tiap posisi. Penelitian ini merupakan penelitian analitik dengan metode penelitian eksperimental. Lokasi penelitian ini yaitu bertempat di RSUD Dr. M. Haulussy Ambon dengan jumlah sampel yang digunakan sama dengan populasi. Berdasarkan uji t-test membuktikan bahwa terdapat perbedaan yang signifikan antara tekanan darah sistol dan diastol dari tiap perlakuan. Nilai rata-rata tekanan darah sistol atau mean untuk kelompok Supine adalah sebesar 113,3495 mmHg, sementara untuk kelompok Left lateral adalah sebesar 117,8990 mmHg. Sedangkan nilai rata-rata tekanan darah diastol atau mean untuk kelompok Supine adalah sebesar 67,0155 mmHg, sementara untuk kelompok Left lateral adalah sebesar 72,2500 mmHg. Dari data tersebut dapat disimpulkan bahwa $\mathrm{H0}$ ditolak dan Ha diterima. Hal tersebut membuktikan bahwa hemodinamika pasien sectio caesarea post anestesi spinal dengan perlakuan left lateral $15^{\circ}$ lebih stabil dibandingan dengan hemodinamika pasien section caesarea post anestesi spinal dengan perlakuan berbaring terlentang.
\end{abstract}

Kata Kunci: Anestesi spinal, tekanan darah, posisi, efedrin.

\begin{abstract}
The thesis is titled "Comparison of hemodynamic stability between Left Lateral position $15^{\circ}$ with Supine Position in the patient's Sectio Caesarea Post Spinal Anesthesia". This thesis is a research study on the effectiveness of the number of doses of ephedrine drugs used in maintaining the hemodynamic stability given in sectio caesarea patient post the spinal anesthetic between the left lateral position $15^{\circ}$ with supine position at the Hospital Dr. M. Haulussy Ambon. The assessment indicators in this thesis include the comparison of position, blood pressure, pulse rate, and the dose of ephedrine used in each position. This research is analytic research with experimental research methods. The location of this research is located at the Hospital Dr. M. Haulussy Ambon with the number of samples used equal to the population. Based on the T-test test, there is a significant difference between the blood pressure of the systole and diastol of each treatment. The average value of blood pressure systole or the mean for the supine group is 113.3495 mmhg, while for the Left lateral group it is 117.8990 mmh. While the average value of diastol blood pressure or mean for the Supine group is $67.0155 \mathrm{mmHg}$, while for the Left lateral Group it is $72.2500 \mathrm{mmHg}$. From that data it can be concluded that $\mathrm{HO}$ rejected and Ha accepted. It proved that the haemodynamics of the patients 'sectio Caesarea post https://ojs3.unpatti.ac.id/index.php/pameri/index


spinal anesthesia with $15^{\circ}$ left lateral treatment is more stable compared with the patient's hemodynamics section Caesarea post spinal anesthesia with a lying down treatment.

Keywords: spinal anesthesia, blood pressure, position, ephedrine.

\section{Pendahuluan}

Persalinan sectio caesarea adalah persalinan melalui sayatan pada dinding abdomen dan uterus yang diambil masil utuh dengan berat janin lebih dari 1000 gram atau umur kehamilan lebih 28 minggu. Keputusan untuk melakukan persalinan sectio caesarea diharapkan dapat menjamin turunnya tingkat morbiditas dan mortalitas. Sectio caesarea digunakan ketika persalinan pervaginam tidak mungkin untuk dilakukan atau memiliki resiko tinggi terhadap ibu dan bayi. Saat persalinan sectio caesarea tidak akan merasakan sakit, tetapi rasa sakit itu akan dirasakan beberapa jam setelah tindakan sectio caesarea selesai. ${ }^{1}$

Proses persalinan dengan menggunakan metode sectio caesarea perlu diperhatikan dengan serius, karena proses persalinan ini memiliki resiko yang dapat membahayakan keadaan ibu dan janin yang sedang dikandung. Angka kematian secara sectio caesarea adalah 40-80 tiap 100.000 kelahiran hidup. Angka ini menunjukan resiko 25 kali lebih besar dibandingkan dengan persalinan pervaginam. $^{2}$ Pada kasus karena infeksi mempunyai angka 80 kali lebih tinggi dibandingkan persalinan pervaginam dan komplikasi dari tindakan anestesi sekitar 10\% dari seluruh angka kematian ibu. ${ }^{3}$
Pembedahan secara caesar sering dilakukan sebagai suatu pilihan operatif yang elektif maupun pada keadaan emergensi. ${ }^{4}$ Indikasi paling umum adalah kegagalan kemajuan pembukaan jalan lahir, gawat janin, disproporsi sefalopelvik, letak janin yang abnormal, prematur, dan juga riwayat sectio caesarea sebelumnya. Teknik anestesi yang digunakan adalah anestesi regional atau umum yang memiliki keuntungan dan juga kerugiannya. Pilihan teknik anestesi tergantung pada indikasi operasi, derajat urgensi, keadaan ibu, dan juga keinginan pasien. ${ }^{5,6}$

\section{International Obstetric Anaesthesia} Guidelines merekomendasikan penggunaan teknik anestesi spinal atau epidural dibandingkan dengan anestesi umum pada sebagian besar kasus sectio caesarea. Anestesi spinal mengakibatkan hipotensi melalui blokade pada saraf simpatis yang berfungsi mengatur tonus otot pembuluh darah. Blokade saraf simpatis preganglionik menyebabkan terjadinya vasodilatasi vena, sehingga terjadi pergeseran volume darah terutama ke bagian splanik dan juga ke extremitas inferior, sehingga menurunkan aliran darah balik ke jantung. Selain itu, hal ini juga menyebabkan terjadinya penurunan resistensi pembuluh darah..$^{5,7,8}$ 
Hipotensi merupakan salah satu efek samping anestesi spinal yang dilakukan pada wanita hamil dengan angka kejadian sekitar 80\%. ${ }^{9,10}$ Efek kardiovaskular ini diakibatkan oleh tindakan anestesi spinal yang berhubungan erat dengan level blokade simpatis yang mencapai persarafan setinggi thorakal satu sampai dengan lumbal dua (T1L2). ${ }^{7,8}$

Berdasarkan World Health Report tahun 2010, didapati bahwa angka kejadian hipotensi dengan pemberian prehidrasi ringer laktat sebanyak $15 \mathrm{ml} / \mathrm{kgBB}$ sebelum anestesi spinal pada suatu grup kontrol yang menjalani sectio caesarea dengan teknik anestesi spinal adalah 43,33\%. ${ }^{11}$ Hasil penelitian tahun 2008 di Chulalongkorn, Thailand didapati bahwa insidensi hipotensi pada pasien yang menjalani sectio caesarea dengan anestesi spinal sebesar 52,6\% dari 722 pasien. Masalah serius yang paling sering terjadi akibat anestesi spinal adalah hipotensi berat setelah onset obat tercapai. ${ }^{12}$

Meskipun saat ini anestesi spinal sudah cukup aman, namun dapat juga menimbulkan komplikasi dan yang paling sering adalah hipotensi. Angka kejadian hipotensi akibat anestesi spinal sekitar 1/3 dari seluruh kasus. Penelitian prospektif yang dilakukan pada lebih dari 1.800 pasien yang mendapat anestesi spinal, 26\% diantaranya mengalami komplikasi dan mayoritas yaitu sebanyak $16 \%$ berupa hipotensi. ${ }^{13,14}$
Hipotensi dapat memberikan efek langsung pada bayi. Sistem uteroplasenta tidak memiliki autoregulasi, karena pembuluh darah plasenta sudah berdilatasi penuh. Perfusi uteroplasenta hanya bergantung pada tekanan darah ibu hamil. Batas tekanan darah terendah yang masih dapat dikompensasi untuk menjamin perfusi uteroplasenta manusia yang masih baik sampai saat ini belum dapat ditentukan. ${ }^{15}$

Jika hipotensi yang terjadi cukup berat atau berkepanjangan, dapat menyebabkan terjadinya fetal asidosis. Meta analisis terbaru menegaskan bahwa kejadian fetal asidosis berat yaitu $\mathrm{pH}$ arteri umbilikalis kurang dari 7,10 lebih sering terjadi pada anestesi spinal dibandingkan dengan anestesia general dan epidural. ${ }^{16,17,18}$

Berbagai cara dapat dilakukan untuk mencegah serta menangani hipotensi yang terjadi pada sectio caesarea, antara lain posisi uterus miring ke kiri (sekitar $15^{\circ}$ ) dengan cara mengganjal pelvis atau memiringkan meja, posisi sedikit head up setelah penyuntikan obat anesthesia local hiperbarik, pemberian cairan kristaloid atau koloid sebelum melakukan anestesi spinal, dapat juga diberikan vasopressor seperti efedrin, penilefrin, atau dopamine. Biasanya obat yang sering diberi adalah efedrin yang diberikan secara intravena dengan dosis 5-10 mg. cara lainnya yang dapat dilakukan adalah elevasi tungkai bawah. ${ }^{6}$ 
Berdasarkan penelitian yang sudah dilakukan, didapatkan bahwa penurunan tekanan darah rata-rata dari $124 / 72 \mathrm{mmHg}$ menjadi 63/38 mmHg pada ibu yang diposisikan terlentang setelah dilakukan tindakan anestesi spinal pada sectio caesarea. Sedangkan pada posisi miring, tekanan darah arteri rata-rata menjadi 100/60 mmHg. ${ }^{19,20}$

Autotransfusi dengan posisi head down dapat menambah kecepatan preload. Jika hipotensi tidak membaik setelah diberikan cairan, maka vasopressor langsung ataupun tidak langsung dapat segera diberikan seperti efedrin dengan dosis 5-10 mg bolus intravena. Efedrin merupakan vasopressor yang akan meningkatkan kontraksi otot jantung (efek sentral) dan bersifat vasokonstriktor (efek perifer). ${ }^{16}$ Efedrin akan merangsang reseptor alfa dan beta adrenergik. Alfa dan beta adrenergik ini akan menghambat vasodilatasi. Efedrin yang diberikan secara intramuscular dan infus kontinyu terbukti dapat mencegah terjadinya hipotensi akibat anestesi spinal pada sectio caesarea. Efedrin intramuscular dengan dosis $45 \mathrm{mg}$ pada wanita hamil dengan berat badan 75-80 $\mathrm{kg}$ efektif mencegah hipotensi sebanyak $48 \%$. Sedangkan apabila diberikan efedrin secara infus kontinyu dengan bolus $6 \mathrm{mg}$ dan dilanjutkan dengan dosis pemeliharaan 2 $\mathrm{mg} / \mathrm{menit}$ efektif menurunkan angka kejadian hipotensi sebesar $41 \%{ }^{16}$
Metode

Penelitian ini merupakan penelitian analitik, dengan menggunakan data primer pasien yang di sectio caesarea untuk mengetahui perbandingan kestabilan hemodinamika antara posisi left lateral $15^{\circ}$ dengan berbaring terlentang pada pasien sectio caesarea post anestesi spinal RSUD Dr. M. Haulussy Ambon Periode Agustus sampai September 2019 dengan metode total sampling berjumlah 40 sampel. Populasi dalam penelitian ini adalah pasien yang dilakukan sectio caesarea post anestesi spinal dengan American Society of Anesthesiologists Physical Status (ASA PS) atu dan dua, serta usia 20 tahun sampai dengan kurang dari 40 tahun. Penelitian ini menggunakan metode Experimental. Pengambilan sampel dengan metode ini bertujuan untuk mencari sampel minimal untuk masing-masing kelompok kasus. Sampel untuk tiap perlakuan akan ditentukan dengan menggunakan urutan. Pasien yang dengan urutan ganjil akan mendapatkan perlakuan berbaring terlentang, dan pasien dengan urutan genap akan mendapatkan perlakuan posisi left lateral $15^{\circ}$.

\section{Hasil}

Hasil yang didapatkan menunjukkan nilai rata-rata tekanan darah sistol untuk kelompok supine adalah sebesar 113,3495 $\mathrm{mmHg}$, sementara untuk kelompok left lateral $15^{\circ}$ adalah sebesar $117,8990 \mathrm{mmHg}$. 
Sedangkan tekanan darah diastol untuk kelompok supine adalah sebesar 67,0155 $\mathrm{mmHg}$, sementara untuk kelompok left lateral $15^{\circ}$ adalah sebesar $72,2500 \mathrm{mmHg}$. Rata-rata denyut nadi pada kelompok supine adalah 92,8990 kali per menit, sedangan pada kelompok left lateral $15^{\circ}$ adalah 91,0990 kali per menit.

Tabel 4.1 Perbandingan tekanan darah sistol pada pasien sectio caesarea

\begin{tabular}{ccc}
\hline Posisi & Supine & $\begin{array}{c}\text { Left Lateral } \\
\mathbf{1 5}^{\circ}\end{array}$ \\
\hline Rata-rata sistol & $113,3495 \mathrm{mmHg}$ & $117,899 \mathrm{mmHg}$ \\
Rata-rata diastole & $67,0155 \mathrm{mmHg}$ & $72,2500 \mathrm{mmHg}$ \\
Rata-rata denyut & $92,8990 \mathrm{kali} \mathrm{per}$ & $91,0990 \mathrm{kali}$ per \\
nadi & menit & menit \\
\hline
\end{tabular}

Hasil penelitian menunjukkan pada posisi supine, rata-rata dosis efedrin yang digunakan pada pasien sectio caesarea yaitu 11,5 mg. Sedangkan pada posisi left lateral $15^{\circ}$, didapati dosis efedrin yang digunakan yaitu $0 \mathrm{mg}$ atau tidak menggunakan efedrin sama sekali selama pasien dimiringkan selama 6 menit setelah anestesi spinal.

Tabel 4.2 Perbandingan dosis efedrin yang digunakan pasien sectio caesarea

\begin{tabular}{ccc}
\hline No & Posisi & Rata-rata Dosis Efedrin \\
\hline 1 & Supine & $11,5 \mathrm{mg}$ \\
2 & Left Lateral & \\
$15^{\circ}$ & $0 \mathrm{mg}$ \\
\hline
\end{tabular}

Hasil analisis Independent sample ttest pada tekanan darah sistol antara kelompok supine dengan kelompok left lateral $15^{\circ}$ diperoleh nilai hitung tabel $\mathrm{t}$ sebesar 1,517 dengan tingkat signifikansi nilai https://ojs3.unpatti.ac.id/index.php/pameri/index p yaitu 0,0138 berarti terdapat perbedaan yang signifikan antara tekanan darah sistol antara kelompok supine dengan kelompok left lateral $15^{\circ}$, dimana rata-rata tekanan darah kelompok supine lebih rendah dibandingkan kelompok left lateral $15^{\circ} \quad(113,3495<$ 117,8990).

Hasil analisis Independent sample ttest pada tekanan darah diastole antara kelompok supine dengan kelompok left lateral $15^{\circ}$ diperoleh nilai hitung tabel $\mathrm{t}$ sebesar 2,285 dengan tingkat signifikansi nilai p yaitu 0,028 sehingga keputusan uji adalah H0 ditolak yang berarti terdapat perbedaan yang signifikan antara tekanan darah diastol antara kelompok supine dengan kelompok left lateral $15^{\circ}$, dimana rata-rata tekanan darah kelompok supine lebih rendah dibandingkan kelompok left lateral $15^{\circ} \quad(67,0155<$ $72,2500)$.

Tabel 4.3 Analisis Independent Sample t-test Tekanan Darah

\begin{tabular}{|c|c|c|c|c|}
\hline \multicolumn{4}{|c|}{ Standar Deviasi } & \multirow[b]{2}{*}{ Nilai $p$} \\
\hline $\begin{array}{c}\text { Tekanan } \\
\text { Darah }\end{array}$ & Supine & $\begin{array}{c}\text { Left } \\
\text { Lateral } \\
15^{\circ} \\
\end{array}$ & tHitung & \\
\hline Sistol & 8,08219 & 10,70209 & $-1,517$ & 0,0138 \\
\hline Diastol & 7,56568 & 6,90756 & $-2,285$ & 0,028 \\
\hline
\end{tabular}

Hasil analisis Independent sample ttest pada denyut nadi antara kelompok supine dengan kelompok left lateral $15^{\circ}$ diperoleh nilai thitung sebesar 0,487 dengan tingkat signifikansi nilai $\mathrm{p}$ yaitu 0,629 sehingga keputusan uji adalah Ha ditolak yang berarti tidak terdapat perbedaan yang signifikan 
denyut nadi antara kelompok supine dengan kelompok left lateral $15^{\circ}$.

\section{Pembahasan}

Pada penelitian ini didapatkan hasil yang menunjukkan tekanan darah sistol pada left lateral $15^{\circ}$ didapati lebih stabil. Pada posisi left lateral $15^{\circ}$, tekanan darah sistol sebesar $117,899 \mathrm{mmHg}$, sedangkan pada posisi supine sebesar 113,3495 mmHg. Tekanan darah diastol pada left lateral $15^{\circ}$ didapati lebih stabil. Pada posisi left lateral $15^{\circ}$, tekanan darah diastol sebesar 72,2500, sedangkan pada posisi supine sebesar 67,0155 $\mathrm{mmHg}$.

Tabel 4.7 Analisis Independent Sample t-test Denyut Nadi

\begin{tabular}{cccc}
\hline Denyut Nadi & $\begin{array}{c}\text { Standar } \\
\text { Deviasi }\end{array}$ & tHitung & $p$ - $v$ \\
\hline $\begin{array}{c}\text { Supine } \\
\text { Left Lateral } \\
15^{\circ}\end{array}$ & $\begin{array}{c}13,75217 \\
\end{array}$ & 0,487 & 0,629 \\
\hline
\end{tabular}

Hal ini diakibatkan ketika pasien hamil dan diposisikan terlentang, maka uterus akan menekan aortokaval sehingga akan mengakibatkan terjadinya penurunan alirah darah yang mengalir ke bagian extremitas inferior dan ke bagian splanik. Hal ini akan mengakibatkan terjadinya penurunan aliran darah balik ke jantung yang disebabkan oleh berkurangnya aliran darah ke daerah tersebut. Sehingga, aliran darah balik ke jantung akan semakin berkurang dan menyebabkan terjadinya penurunan pada aliran darah ke seluruh tubuh. ${ }^{7,8}$

Hipotensi dapat memberikan efek langsung pada bayi. Sistem uteroplasenta tidak memiliki autoregulasi, karena pembuluh darah plasenta sudah berdilatasi penuh. Perfusi uteroplasenta hanya bergantung pada tekanan darah ibu hamil. Batas tekanan darah terendah yang masih dapat dikompensasi untuk menjamin perfusi uteroplasenta manusia yang masih baik sampai saat ini belum dapat ditentukan. ${ }^{15}$

Pada saat ibu hamil di miringkan $15^{\circ}$, maka tidak akan terjadi penekanan pada aortokaval, sehingga tidak akan terjadi penurunan aliran darah yang kaya akan oksigen ke bagian extremitas inferior dan ke bagian splanik. Hal ini akan mengakibatkan tidak terjadinya penurunan aliran darah balik ke jantung. Sehingga ibu hamil tidak akan mengalami hipotensi. ${ }^{7}$

Hal ini sesuai dengan penelitian yang dilakukan oleh Ueland yang mengatakan adanya perubahan hemodinamika pada pasien yang menjalani section caesarea dengan anestesi spinal. Pada posisi terlentang, di dapati terjadi penurunan rata-rata tekanan darah dari 124/72 mmHg menjadi 78/63 mmHg. Pada pasien yang telah mendapatkan anestesi spinal akan terjadi blok pada serabut saraf preganglionik otonom yang merupakan serat saraf halus. Akibat denervasi simpatis ini akan terjadi penurunan tahanan pembuluh 
tepi karena terjadi dilatasi arterial, arteriol, dan post arteriol yang mengakibatkan terjadi hipotensi ringan. Pada pasien sectio caesarea, hipotensi dapat menjadi berat akibat efek yang di timbulkan dari anestesi spinal dan berbaring dengan posisi terlentang atau posisi supine, sehingga terjadi venous pooling yaitu terjadinya kompresi pada aortokaval akibat penekanan oleh Rahim, janin, plasenta, dan cairan ketuban yang beratnya lebih dari 6 kilogram. Penekanan terjadi pada L4-L5 sehingga mengakibatkan penurunan venous return ke jantung, yang nantinya akan menyebabkan terjadinya penurunan cardiac output. Jika cardiac output menurun, maka akan mengakibatkan terjadinya penurunan tekanan darah. ${ }^{7,36}$

Tekanan darah sistole dan diastole setelah 5 menit pemberian posisi miring pada pasien sectio caesarea yang di berikan anestesi spinal, di dapati bahwa tekanan sistole menjadi $112,29 \mathrm{mmHg}$ dan tekanan diastole menjadi 63,12 $\mathrm{mmHg}$, posisi ini ada dalam keadaan normal. Hal ini sesuai dengan penelitian yang di lakukan oleh Ueland bahwa, mengubah posisi pasien dari terlentang menjadi lateral dapat meningkatkan isi sekuncup 44,1\%, menurunkan denyut jantung sebanyak $4,5 \%$ dan meningkatkan curah jantung sebanyak 33,5\%. Nilai tekanan darah selalu berubah-ubah, perubahan tekanan darah ini di pengaruhi oleh factor curah jantung, isi sekuncup atau stroke volume, denyut jantung, tahanan perifer, panjang dan diameter pembuluh darah. Anestesi spinal mengakibatkan terjadinya vasodilatasi pembuluh darah yang akan mengakibatkan terjadinya perubahan diameter pada pembuluh darah sehingga terjadi pengurangan volume kapasitas pembuluh darah. ${ }^{7,36}$

Tindakan operasi atau pembedahan selain dapat menimbulkan nyeri, trauma, juga dapat menimbulkan gejala kardiovaskuler berupa peningkatan tekanan darah, peningkatan laju jantung dan disritmia. Hal ini dikaitkan dengan respon stress dan reflek simpatis yang berlebihan. Anestesi mengubah atau memodifikasi respon stress, yang dapat diubah lebih lanjut dengan menggunakan penggunaan opium dosis tinggi. Selama anestesi, denyut jantung dan tekanan darah dipertahankan dalam batas normal. Sebagian besar pasien akan mempertahankan denyut jantung pasca operasi antara 50 hingga 80 denyut jantung per menit. ${ }^{7,8}$

Penggunaan efedrin di bidang anestesi pada kasus hipotensi akibat anestesi regional, baik oleh karena anestesi spinal maupun anestesi epidural. Pemberian efedrin dengan dosis 10-25 mg intravena pada orang dewasa sebagai pilihan simpatomimetik mengatasi blokade susunan saraf simpatis yang disebabkan anestesi regional ataupun untuk mengatasi efek hipotensi yang disebabkan oleh obat-obat anestesi. Pada ibu hamil yang menjalani sectio caesarea dengan anestesi 
spinal, efedrin merupakan pilihan untuk mengatasi hipotensi yang diakibatkan oleh anestesi spinal. Efedrin juga dapat meningkatkan tekanan darah dan memperbaiki aliran darah plasenta. Selain itu, efedrin juga digunakan untuk mengatasi hipotensi akibat induksi dengan propofol. Efedrin dapat mempercepat kerja dari rokunorium. ${ }^{16}$

Efek kardiovaskular dari efedrin menyerupai epinefrin, tetapi respon kenaikan tekanan darah sistemik kurang disbanding efedrin. Efedrin membutuhkan 250 kali dibandingkan epinefrin untuk mendapatkan efek kenaikan tekanan darah yang sama. Pemberian efedrin intravena meningkatkan tekanan darah, denyut jantung, dan curah jantung. Aliran darah renal dan splanik menuruh, tetapi aliran darah coroner dan otot skelet meningkat. Resistensi vascular sistemik berubah karena vasokonstriksi pada vascular beds diimbangi dengan vasodilatasi oleh stimulasi beta-2 pada tempat-tempat yang lain. Efek kardiovaskular tersebut pada reseptor alfa menyebabkan vasokonstriksi arteri dan vena di perifer. Mekanisme utama efek efedrin terhadap kardiovaskular adalah dengan meningkatkan kontraktilitas otot jantung dengan aktivasi reseptor beta-1. Dengan adanya antagonis reseptor beta, maka efek efedrin terhadap kardiovaskular adalah dengan stimulasi reseptor alfa. ${ }^{16}$
Efedrin akan merangsang reseptor alfa dan beta adrenergik. Alfa dan beta adrenergik ini akan menghambat vasodilatasi. Efek samping pemberian efedrin yaitu cemas, palpitasi, dan insomnia. Sedangkan efek pada kardiovaskular yang tidak menguntungkan berupa kenaikan tekanan darah sampai takikardi. Kenaikan tekanan darah yang tinggi dan mendadak sampai melebihi batas kemampuan autoregulasi otak akan berakibat terjadi hiperfusi dan kebocoran cairan melalui sawar darah otak sehingga menimbulkan edema otak dengan gejala klinis sakit kepala hebat,rasa mengantuk, bingung sampai kejang bahkan penurunan kesadaran. ${ }^{16}$

Penelitian ini memiliki keterbatasan yaitu alat ukur yang digunakan hanya bisa menilai posisi left lateral $15^{\circ}$.

\section{Kesimpulan}

1. Ada perbedaan yang signifikan antara rata-rata tekanan darah sistol pada kelompok Supine dengan kelompok Left lateral dengan nilai $\mathrm{p}$ yaitu 0,0138 .

2. Ada perbedaan yang signifikan antara rata-rata tekanan darah diastol pada kelompok Supine dengan kelompok Left lateral dengan nilai p yaitu 0,028 .

3. Tidak ada perbedaan yang signifikan antara rata-rata denyut nadi pada kelompok Supine dengan kelompok Left lateral dengan nilai p yaitu 0,629. 
4. Dosis efedrin yang digunakan pada posisi supine yaitu $11,5 \mathrm{mg}$. Sedangkan pada posisi left lateral $15^{\circ}$, tidak menggunakan efedrin selama pasien dimiringkan 6 menit post anestesi spinal.

5. Hasil analisis pada penelitian ini menunjukkan bahwa hemodinamika pasien sectio caesarea post anestesi spinal dengan perlakuan posisi left lateral $15^{\circ}$ lebih stabil dibandingkan dengan berbaring terlentang.

\section{Saran}

Berdasarkan hasil penelitian ini, peneliti memberikan saran sebagai berikut:

1. Perlu diadakan penelitian lanjutan mengenai perbandingan kestabilan hemodinamika antara berbaring terlentang dengan posisi left lateral $15^{\circ}$ pada pasien sectio caesarea post anestesi spinal di RSUD Dr. $M$. Haulussy Ambon.

2. Perlu dilakukan penelitian lanjutan tetapi menggunakan sudut yang lebih kecil seperti $10^{\circ}$ sesuai dengan penelitian yang telah dilakukan oleh Salman $\mathrm{OH}$ dan teman-teman tetapi didapatkan hasil yang tetap sama.

3. Bagi RSUD Dr. M. Haulussy Ambon, pasien sectio caesarea perlu dimiringkan selama 6 menit setelah di anestesi spinal dalam menjaga kestabilan hemodinamika pasien dan juga dalam jumlah dosis efedrin yang diberikan lebih sedikit.

4. Perlu dilakukan penelitian lanjutan dengan jangka waktu yang lebih lama sehingga diharapkan mendapatkan hasil denyut nadi yang lebih signifikan.

\section{Referensi}

1. Ngan Kee WD. Prevention of maternal hypotension after regional anaesthesia for caesarean section. Curr Opin Anaesthesiol. 2010;23. p: 304-9.

2. Gibbons L, Belizam JM, Lauer JA, et all. World Health Report. The Global Numbers and Costs of Additionally Need and Unnecessary Caesarean Sections Performed per Year. (internet). 2010. Available from : http://www.who.int/healthsystems/topics/ financing/healthreport/30Csectioncosts.pdf.

3. Benson R, Pernoll M. Handbook of Obstetric and Gynecologic. 10 $0^{\text {th }}$ edition. New York: The McGraw Hill Companies. 2009.

4. Baraka A, MD, FRCA. Editorial: can we minimize hypotension following spinal anesthesia for caesarian section. MEJ Anesth. 2010:p. 5-20.

5. Depkes RI. Profil Kesehatan Indonesia. Depkes RI. Jakarta. 2010.

6. Depkes RI. Pengelolahan Program KIA. Depkes RI. Jakarta. 2009.

7. Salman $\mathrm{OH}$, Yehia AH. Randomized double-blind comparison of intravenous ephedrine and hydroxyethyl starch $6 \%$ for spinal-induced hypotension in elective caesarean section. Ain-Shams Anesthesiol. 2014;07. p: 221-5.

8. Chumpathong $\mathrm{S}$, Chinachoti $\mathrm{T}$, Visalyaputra S, Himmungan T. Incidence and risk factors of hypotension during spinal anesthesia for caesarean section at Siriraj Hospital. J Med Assoc Thai. 2006;89(8). p: 1127-32. 
9. Baraka A, MD, FRCA. Editorial: can we minimize hypotension following spinal anesthesia for caesarian section. MEJ Anesth. 2010:p. 5-20.

10. Somboonviboon W, Kyokong O, Narasethakamol A. Incidence and risk factors of hypotension and bradycardia after spinal anesthesia for caesarian section. J Med Assoc Thai. 2008;91(2). p: 181-7.

11. Gibbons L, Belizam JM, Lauer JA, et all. World Health Report. The Global Numbers and Costs of Additionally Need and Unnecessary Caesarean Sections Performed per Year. (internet). 2010. Available from : http://www.who.int/healthsystems/topics/ financing/healthreport/30Csectioncosts.pdf.

12. Surya SL. Perbandingan Efek Koloading HES dan Ringer Laktat terhadap Hipotensi Akibat Spinal Anestesia Pada Wanita Hamil Ynag Menjalani Seksio Sesarea. Tesis PPDS Anestesiologi dan Terapi Intesif. Sumatera: FK USU.2011.

13. Carpnter RL, Caplan RA, Brown DL. Incidence and risk factors for side effects of spinal anesthesia. The Journsl of The American Society of Anesthesiologist. Vol 76. 2002. Available from: http://journals.lww.com/anesthesiology/A bstract/1992/0600/Incidence_and_Risk_F actors_for_Side_effects_of.6.aspx

14. Rofiq A, Sutiyono D. Anestesia Regional dan Umum Pada Operasi Caesar, Jurnal Anestesiologi Indonesia. Volume 1(3). Semarang: FK Undip. 2009. p:185-200.

15. Heriwardito A. Perbandingan Hemodinamik saat Anestesi Spinal antara Coloading Ringer Laktat dan HES 130/0,4 untuk Operasi Bedah Sesar. Anestesia \& Critical Care. Volume 28(2). 2010. p: 7.

16. Velde MV. Spinal anesthesia in the obstetric patient: prevention and treatment of hypotension. Acta Anaesthesiologica Belgica. Volume 57. 2006. p: 383-6.

17. Mitra JK, Roy J, Bhattacharyya P, Yunus M, Lyngdoh NM. Changing trends in the management of hypotension following spinal anesthesia in caesarean section. $\mathbf{J}$ Postgrad Med. 2013;59. p: 121-6.

18. Harten JM, Boyne I, Hannah P, Ververis D, Brown A. Effect of a height and weight adjusted dose of local anaesthetic for spinal anaesthesia for elective caesarean section. Anaesthesia. 2005;60. p: 348-53

19. Chesnut DH, Polley LS, Tsen LC, Wong CA. Obstetric anaesthesia, principles and practice. Edisi 4. Philadelphia: Mosby Elseiver;2009.

20. Bieniarz J, Maqueda E, Caldeyro-Barcia R. Compression of aorta by the uterus in late human pregnancy. I. Variations between femoral and brachial artery pressure with changes from hypertension to hypotension. Am. J. Obstet. Gynecol. 1966 Jul 15;95(6):795-808. [PubMed]

21. Afolabi BB, Lesi FEA, Merah NA. Regional versus general anesthesia for caesarean section (Review). The Cochrane Collaboration. 2006;4. p:1-44.

22. Birnbach DJ. General anesthesia for caesarean section-who needs it? European Society of Anaesthesiologists, Refresher Course. 2003. p: 165-7.

23. Flora L, Redjeki SI, Wargahadibrata HA. Perbandingan efek anestesi spinal dengan anestesi umum terhadap kejadian hipotensi dan nilai APGAR bayi pada seksio sesaria. Jurnal Anestesi Perioperatif. 2014;2:105-6.

24. Ronald D, Miller MD. Anesthesia. $6^{\text {th }}$ edition. New York: Churchill Livingstone. 2005: p. 232-329.

25. Barbeau TR. Cardiovascular physiology. Florence: Francis Marion University. 2004.

26. Cunningham $F$ et al. Obstetri Williams. Volume 1. Ed.23.- Jakarta : EGC, 2012.

27. Anggorowati, Sudiharjiani Nanik. Mobilisasi dini dan penyembuhan luka operasi pada ibu post sectio caesarea (SC) di ruang Dahlia Rumah Sakit Umum Daerah Kota Salatiga. [Available from : http://jurnal.unimus.ac.id/index.php/psn1 2012010/article/viewFile/1281/1334] Akses: 4 April 2019.

28. Cunningham Gary F, Leveno J K, Bloom. S L, Haut. C J, Rouse. J D, Spongg. Y C. Obstetri William. Ed.23.Vol.1- Jakarta: EGC. 2012.

29. Snell R.S. Anatomi klinik untuk mahasiswa kedokteran.Ed.6.Jakarta: EGC. 2006.

30. Sander A. M. Antibiotika rasional dalam Ilmu Bedah. Fakultas Kedoteran 
Universitas Muhamadiyah Malang. [Available from : http://ejournal.umm.ac.id/index.php/farm asains/article/download/1160/1251]Akses : 4 April 2019.

31. Obstetri Patologi. Bagian obstetri dan ginekologi Fakultas Kedokteran Universitas Padjadjaran Bandung. Bandung: Elstar Offset, 1984.

32. Moore L. K, Agur R.M.A. Anatomi dasar klinis.Jakarta: Hipokrates. 2002.
33. Gibson. J. 2002. Fisiologi dan Anatomi Modern untuk Perawat. Ed. 2. EGC. Jakarta. Pp : 123.

34. Werner. D. 1980. Where There is No Doctor . Hesperian Foundation. Ed 1. USA. Pp : 161.

35. Reid, W.D. Clinical Management Notes and Case Histories in Cardiopulmonary Physical Therapy. United State of America: Slack. 2004.

36. Potter PA., Perry AG., Elkin MK. Nursing Interventions \& Clinical Skills. St. Louis: Missouri USA. 2006. 